\title{
REVISTAMARACANAN
}

Dossiê

\section{Os indesejados da seca: a imagem do sertanejo desde as narrativas da Revista do Instituto do Ceará ao Campo de Concentração do Alagadiço (1887-1915)}

\author{
The unwanted from drought: the image of the sertanejo from the narratives \\ of the Instituto do Ceará journal to the Alagadiço Concentration Camp \\ (1887-1915)
}

Recebido em: 14 set. 2020.

Aprovado em: 9 nov. 2020.

Leda Agnes Simões de Melo*

Pesquisadora Independente

Rio de Janeiro, Rio de Janeiro, Brasil

Camila de Sousa Freire**

Universidade do Estado do Rio de Janeiro

Rio de Janeiro, Rio de Janeiro, Brasil

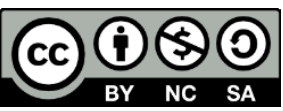

\footnotetext{
* Pesquisadora independente. Doutora em História Social pela Universidade do Estado do Rio de Janeiro; Mestre em Ciências Sociais (Desenvolvimento, Agricultura e Sociedade) pela Universidade Federal Rural do Rio de Janeiro; graduada em História pela Universidade Federal Fluminense. E-mail: ledagnes@hotmail.com

(iD) https://orcid.org/0000-0002-6247-5584 (6) http://lattes.cnpq.br/5719284549348847

** Doutoranda no Programa de Pós-graduação em História Social da Faculdade de Formação de Professores da Universidade do Estado do Rio de Janeiro. Mestre em História Social e graduada em História pela Universidade do Estado do Rio de Janeiro. E-mail: freirecamila96@gmail.com

(D) https://orcid.org/0000-0002-6096-0615 (9) http://lattes.cnpq.br/5004087582721999
} 


\title{
Resumo
}

O presente artigo trata das imagens construídas sobre o sertanejo, desde as narrativas do Instituto do Ceará até a criação do campo de concentração do Alagadiço, na seca de 1915. Para isso, analisaremos como o Instituto do Ceará, criado em 1887, através da sua Revista do Instituto do Ceará, vinculou o pioneirismo cearense em relação à abolição da escravatura também ao fato da província ser acometida pela seca. A ideia da natureza ser condicionante da vida da região e ser uma narrativa construída historicamente para retratar o Ceará, fez parte do pensamento da elite que estava à frente do Instituto, e é parte fundamental do que se vai narrar sobre os sertões, os sertanejos, seus costumes, seus modos de ser e agir nos anos posteriores. Nesse sentido, a seca ganha espaço como campo de lutas que também são simbólicas, e justificam medidas segregadoras e excludentes como o campo de concentração do Alagadiço. Por meio de ofícios e relatórios do governo e da Inspetoria de Obras Contra as Secas (IOCS), propomos uma reflexão acerca dos discursos que estavam na ordem do dia na seca de 1877 e que fizeram parte da narrativa da própria criação do campo do Alagadiço em 1915.

Palavras-chave: Revista Instituto do Ceará. Campo de Concentração do Alagadiço. Seca. Sertanejos.

\begin{abstract}
This present article concerns the image built upon country people, from the narratives of the Instituto do Ceará to the creation of the concentration camp of Alagadiço, in the 1915 drought. In order to do that, we will analyze how the Instituto do Ceará, created in 1887, through its Instituto do Ceará journal, attached Ceará's leading position in the abolition of slavery to the fact that the province was being striked by a drought period. The idea of nature as a life conditioner of the region is a narrative historically built to represent Ceará, and was a part of the Instituto do Ceará leading elite's line of thinking, and is a fundamental part of what is going to be said about the countryside, country people, its manners and way to be and act for many years to come. That way, the drought gains space as a field for a dispute that is also symbolic, and that justify the segregating and excluding measures like the concentration camp of Alagadiço. We propose a reflection around the speeches that were in order back in the 1877 drought and which were part of the narrative in the very own creation of the concentration camp of Alagadiço, in 1915, through crafts and reports from the government and the Inspetoria de Obras Contra as Secas [Inspectorate of Works Against Droughts] (IOCS).
\end{abstract}

Keywords: Instituto do Ceará Journal. Concentration Camp of Alagadiço. Drought. Sertanejo. 
Nordeste é uma ficção! Nordeste nunca houve! Não! Eu não sou do lugar dos esquecidos! Não sou da nação dos condenados! Não sou do sertão dos ofendidos! Você sabe bem: Conheço o meu lugar!

Belchior. "Conheço o meu lugar".

\section{Introdução}

A epígrafe que abre este artigo é uma letra da canção do cantor e compositor Belchior lançada em 1979, em seu disco Era uma vez um homem e o seu tempo. Antônio Carlos Gomes Belchior Fontenelle Fernandes nasceu em Sobral, no Ceará, em 1946. Em 1962, migrou para Fortaleza e, ainda jovem, em 1971, saiu do Ceará para viver no Rio de Janeiro. Toda sua trajetória musical foi marcada por suas andanças e pelo fato de ter sido um nordestino que migrou para o sudeste. Diversas das suas canções refletem os muitos preconceitos que viveu na grande metrópole do Rio de Janeiro, ou mesmo em São Paulo. Em "Fotografia 3x4", outra composição de sua autoria, ele escrevia em primeira pessoa: "Em cada esquina que eu passava um guarda me parava / Pedia os meus documentos e depois sorria / Examinando o $3 \times 4$ da fotografia / E estranhando o nome do lugar de onde eu vinha". ${ }^{1}$

No trecho acima, que abre este trabalho, da canção "Conheço meu lugar", Belchior diz que o Nordeste é uma fiç̧ão, que o Nordeste nunca houve e que ele não pertencia a nação dos esquecidos, condenados, nem do sertão dos ofendidos. Neste sentido, a partir das provocativas de Belchior, desejamos refletir sobre a construção de uma narrativa sobre o Nordeste, logo, do lugar ocupado por essa região no imaginário nacional e ainda, mais especificamente, sobre como isso se deu no Ceará do final do século XIX e início do século XX. Buscamos refletir como, por meio de algumas imagens, visões e símbolos, se solidificaram ideias sobre essa região, construídas inclusive dentro do próprio estado do Ceará.

Partimos da premissa levantada nos estudos de Durval Muniz de Albuquerque Júnior sobre a "invenção do Nordeste", em que ele aponta caminhos de entendimentos possíveis sobre sua criação enquanto região, que acreditamos ter implicações claras no Ceará e, mais precisamente, nos seus sertões. O autor nos convida a pensar a história de uma região, ou de um dado local, a partir de uma desconstrução de fatos que são naturalizados historicamente. Para isso, ele nos convoca a fazer uma reflexão sobre o espaço não como mero cenário, mas

\footnotetext{
${ }^{1}$ Originalmente em: BELCHIOR. Fotografia 3x4. Alucinação. Rio de Janeiro: PolyGram, 1976. Long play
} (5 min. e 27 seg.). 
como fruto dos acontecimentos históricos. Nesse sentido, a natureza, o relevo, os regimes das chuvas e dos ventos, o curso dos rios, são também elementos que ganham historicidade. ${ }^{2}$

Consideramos propor uma reflexão que leve a cabo uma compreensão do nível dos sentidos, dos discursos, dos significados sociais que estão imbricados na formação de uma região. Como analisa Albuquerque Júnior, devemos pensá-la não como algo anterior aos discursos ou "aos relatos que a definem, nomeiam, relatam, atribuem sentido e significado". ${ }^{3}$ Ela deve ser dada como um "trabalho de subjetivação [...] uma incorporação consciente ou não das narrativas que definem este ser regional". ${ }^{4}$

Por meio desse itinerário proposto por Albuquerque Júnior, nos valeremos de dois momentos, em específico, para pensar os discursos sobre o Ceará: Primeiro, o da criação do Instituto Histórico, Geográfico e Antropológico do Ceará em 1887, que vinculou a narrativa sobre o pioneirismo da abolição da escravidão (1884) à seca que acometeu o estado anos antes, entre 1877 e 1879. Logo, a partir do próprio Instituto e dos artigos da Revista do Instituto do Ceará, é possível perceber como se construíram imagens sobre o ser cearense a partir desses fatos. E segundo, como esse tipo de narrativa teve implicações posteriores claras para a população sertaneja em períodos de seca.

Nesse sentido, a seca de 1915, pode mostrar como no Ceará construiu-se uma imagem sobre a região, que é reforçada a cada estiagem que o atinge. Ainda mais, como esses discursos naturalizados ao longo do tempo justificam inclusive medidas concretas para o sertanejo, como a criação do primeiro campo de concentração do Ceará, o campo do Alagadiço. ${ }^{5}$ Por meio de ofícios e relatórios do governo e da Inspetoria Federal de Obras Contra as Secas (IOCS), é possível perceber o pensamento oficial da época em relação às populações dos sertões cearenses, e assim podemos analisar algumas continuidades discursivas no que tange às narrativas provenientes da seca de 1877 .

\footnotetext{
${ }^{2}$ ALBUQUERQUE JÚNIOR, Durval Muniz. Receitas Regionais: a noção de região como um ingrediente da historiografia brasileira ou o regionalismo como um modo de preparo historiográfico. Anais do [...] XIII Encontro de História da ANPUH-Rio. Seropédica, RJ: ANPUH-Rio, 2008, p. 4.

${ }^{3}$ Ibidem, p. 8.

${ }^{4}$ Idem.

5 O sertanejo podia ser um vaqueiro, posseiro, sitiante, um meeiro, ou mesmo um agregado. "José de Souza Martins explica que o sertanejo vivia em uma atividade pastoril, com o trabalho livre do vaqueiro ou dependente de um fazendeiro no caso do agregado, dos sitiantes e posseiros (morador de condição que aos poucos se tornará assalariado). O sertanejo podia ser também um pequeno lavrador e criador de gado, em seu pequeno pedaço de terra [...] muitos sertanejos eram também jagunços e trabalhadores das fazendas do coronel ou de seus clientes [...] Celso Furtado analisa que a estrutura agrária dos sertões nordestinos [...] o que prevalecia era a categoria do meeiro, aquele trabalhador que em terras latifundiárias acabava por trabalhar sob o regime de participação, produzia para poder comer e o excedente da produção era comercializado para o benefício do dono da terra, é o que ele chama de um 'salário de subsistência'. Nessa perspectiva, o ponto fraco para Furtado é esse morador, esse meeiro, o peso maior da seca vai para ele, pelo colapso da produção agrícola, traduzido em fome". MELO, Leda Agnes Simões de. O trabalho em tempos de calamidade: a Inspetoria de Obras nos campos de concentração do Ceará (1915 e 1932). 2015. Dissertação (Mestrado em Ciências Sociais em Desenvolvimento, Agricultura e Sociedade) - Universidade Federal Rural do Rio de Janeiro, Seropédica (RJ), p. 57-58. Sobre as leituras referentes aos sertanejos, ver: MARTINS, José de Souza. Os camponeses e a política no Brasil. As lutas sociais no campo e seu lugar no processo político. Petrópolis, RJ: Vozes, 1983; TAVARES, M. C.; ANDRADE, M. C.; PEREIRA, R. (Entrevistadores). Seca e Poder: entrevista com Celso Furtado. São Paulo: Fundação Perseu Abramo, 1998.
} 


\section{O cearense, a abolição e a seca na narrativa da Revista do Instituto do Ceará}

No contexto da década de 1880, ainda no final do Império, foi fundado o Instituto Histórico, Geográfico e Antropológico do Ceará, em 1887. Foi criado como instituição congênere ao Instituto Histórico e Geográfico Brasileiro (IHGB, 1838), de caráter científico e cultural, com o objetivo de tornar conhecidas a História e a Geografia da província, bem como seus aspectos antropológicos, que contribuíram para a formação da identidade regional, e também para a identidade nacional. Seus fundadores foram homens abastados da capital cearense, entre eles políticos, médicos e jornalistas. ${ }^{6}$ Este seguiu as mesmas características do IHGB, de valorização do documento como indicador da verdade histórica, legitimando a nacionalidade. Sua fundação se deu em um contexto onde agremiações como esta eram caracterizadas por suas práticas intelectuais e políticas, ou seja, imbuídas de um caráter científico, também se interessavam e interferiam politicamente em seu meio social através de suas produções.

Gleudson Passos Cardoso explica que os movimentos intelectuais ocorridos no Ceará entre 1873 e 1904, principalmente nas organizações e movimentos literários, surgiram em uma conjuntura de efervescência intelectual, principalmente em Fortaleza. Alí eram pensados modelos de Estado e nação no período de fim da monarquia e das décadas iniciais do regime republicano. Por isso, acreditamos que o Instituto do Ceará esteve inserido naquele contexto como instituição legitimadora da identidade regional cearense a partir do uso da memória, principalmente da abolição da escravidão, na escrita da História da província. ${ }^{7}$

Cardoso defende que houve nesses espaços letrados a construção de um "ideário ilustrado cearense para o Estado e Nação brasileiros diante da transição política". ${ }^{8}$ Ideário fundamentado em três bases: a chegada das "Luzes" e as ideias eurocêntricas que norteavam o progresso rumo à civilização, que conquistaram espaço entre os intelectuais cearenses naquele período; as secas, que foram interpretadas como uma fase evolutiva, dentro dos conceitos evolucionistas também em voga naquele momento; e a libertação dos escravos em 1884 , tida pelos intelectuais da Mocidade Cearense como uma conquista institucional perante o restante do país. ${ }^{9}$ De acordo com o autor, os órgãos literários daquele momento, através de sua produção, buscavam inserir a população no novo contexto que se formava, fazendo crer que o país adentrava na modernidade e, assim, alcançaria finalmente a civilização e o progresso, ideais caros à República. Nessa mesma perspectiva, o Instituto, com o objetivo de

\footnotetext{
6 SILVA, Ana Paula Barcelos Ribeiro da. "Nem História nem mesmo Chronica": escrita da história, identidade e integração nacional no intercâmbio entre o IHGB e o Instituto do Ceará (1889-1931). Revista do Instituto Histórico e Geográfico Brasileiro, Rio de Janeiro, ano 177, n. 471, p. 101-124, abr.jun. 2016, p. 111.

7 CARDOSO, Gleudson Passos. As Repúblicas das letras cearenses: literatura, imprensa e política (18731904). 2000. Dissertação (Mestrado) - Pontifícia Universidade Católica de São Paulo, São Paulo.

8 Idem.

${ }^{9}$ A Mocidade Cearense foi um movimento letrado ocorrido no Ceará na década de 1870 e que deu origem a agremiações, clubes e sociedades literárias.
} 
tornar conhecida a história da província e a produção destes intelectuais, fundou sua própria revista a Revista do Instituto do Ceará, em 1887, no mesmo ano da sua fundação. Nos artigos analisados da Revista é possível se perceber um claro trabalho de fortalecimento de uma memória coletiva regional que pudesse mostrar o quanto o Ceará contribuiu para a história nacional. Fica clara também a busca pelo reconhecimento de seus supostos feitos e pelo olhar das outras províncias e de outros países, desejo este presente desde o momento em que o movimento abolicionista se desenrolava, e que adentrou o período republicano, na tentativa de cooperação na escrita da história nacional.

Tzvetan Todorov nos esclarece sobre a busca por reconhecimento através do olhar do outro, ${ }^{10}$ aspectos muito presentes nos discursos dos abolicionistas cearenses e dos membros do Instituto. Para ele, o reconhecimento é uma condição inerente à própria existência do ser humano, confirmando-a a partir do outro. Sendo assim, toda coexistência em sociedade é uma constante busca por reconhecimento. É o que percebemos na relação do Ceará com o restante do país, principalmente com o Rio de Janeiro, tanto em 1884 quanto nas primeiras décadas da República, pois o Rio de Janeiro era considerado o centro econômico e político do país.

Por isso, uma narrativa importante que se queria evidenciar, na Revista, era a memória relativa à abolição da escravatura, já que os abolicionistas escreveram diversos artigos para a mesma posteriormente. Esses abolicionistas desejavam deixar para a posteridade à ideia de que o Ceará, apesar de ser uma província pobre, já estava, pela suposta abnegação de seu povo, destinado a conquistar a abolição, bem como às glórias e honras advindas da mesma. E essa abnegação do povo cearense teve origem, segundo essa narrativa, nos sofrimentos causados pela seca. Esta tornou o cearense forte, pela superação das adversidades, ao mesmo tempo que o fez se preocupar com o sofrimento dos escravos, pois ele mesmo também teria sofrido na seca de 1877-1879. Ou seja, esse sofrimento pelo qual passou teria desenvolvido no cearense uma empatia pelo sofrimento do próximo. Assim, nesse discurso, a abolição deriva diretamente da seca. Inclusive o próprio aspecto "antropológico" do nome do Instituto se referia a essa necessidade que se tinha naquele momento de análise do meio e do clima na formação do povo cearense e da própria região. A seca foi abordada pelos movimentos literários da década de 1870 e era vista como resultado do meio e do clima da província, e como determinante social, já que influenciava diretamente a personalidade dos próprios cearenses. Podemos perceber essa ideia no trecho de um texto publicado no tomo comemorativo de cem anos da abolição, na Revista do Instituto do Ceará, em 1984, de autoria de Alba Valdez:

Nascido sob o céo mais ingrato do Brasil, o cearense nunca foi um predilecto da fortuna. No berço, embalou-o o éco plangente de passadas catastrophes e como as demais creanças nem sempre ouviu os contos de fadas, alegres e encantadores, narrados à luz do luar. A actividade que o caracteriza tem albaroado contra frequentes caprichos da natureza. ${ }^{11}$

${ }^{10}$ Cf.:TODOROV, Tzvetan. A vida em comum: Ensaio de Antropologia Geral. São Paulo: Ed. Unesp, 2014.

${ }^{11}$ VALDEZ, Alba. Uma data cearense. Revista do Instituto do Ceará. Fortaleza: Ed. UFC, 1984, p. 244. 
No entanto, estudos mais recentes sobre o tema relatam a atitude de exclusão, isolamento e controle desses retirantes por parte da elite política, que devido à seca saíam do campo e iam para Fortaleza. Ao mesmo tempo em que eram isolados nas regiões periféricas da capital, para não macular o aspecto de civilização da mesma, tinham sua força de trabalho explorada pela elite governamental. Essa elite aproveitava os recursos enviados pelo governo central para a construção de obras de melhoramento do espaço urbano, utilizando a mão de obra desses retirantes. O objetivo era evitar a ociosidade dos mesmos e assim toda ordem de vícios (prostituição, mendicância, entre outros) que estes pudessem propagar; ao mesmo tempo em que disseminavam a ideia de que o recebimento de recursos sem trabalho seria esmola.

A partir das décadas de 1860/70, Fortaleza passou por diversas transformações no âmbito intelectual, político e urbano. José Olivenor destaca que este crescimento ocorreu a partir do incremento no comércio de algodão, principalmente no período da guerra civil norteamericana (1861-1865). ${ }^{12}$ Com essa inserção na economia mundial emergiu uma elite burguesa, assim como os setores médios, como advogados, jornalistas, médicos e engenheiros. Essa elite local, junto com o poder provincial estabeleceu medidas estratégicas para conter qualquer comprometimento a esse progresso. Foi neste momento, a partir da segunda metade do século XIX e início do século $X X$, que ocorreram uma série de "melhoramentos" na cidade de Fortaleza, como, por exemplo, a construção da Santa Casa de Misericórdia (1861), a rede de iluminação pública e o sistema de canalização de água (1871). As obras não pararam por causa da seca de 1877, pelo contrário, a mão de obra utilizada nessas obras era a dos sertanejos retirantes, justamente porque tinham o objetivo de controlá-los, por meio do trabalho. ${ }^{13}$

Essa apropriação pela elite do flagelo dos retirantes, desses indesejados da seca, não era questionada, pois eram atribuídas às condições climáticas todas as misérias pelas quais estes passavam, quando as autoridades tinham meios de aliviá-las e não o faziam. Inclusive alguns jornais chegaram a denunciar o desvio de alimentos e verbas destinadas aos retirantes. ${ }^{14}$ Assim, a criação de um estado de crise foi o meio pelo qual as elites buscaram satisfazer seus interesses econômicos e políticos através de "um conjunto de infraestruturas básicas capaz de proporcionar-Ihes a expansão de seu poder privado". ${ }^{15}$ Assim como controlar essa população, vista como potencialmente perigosa e problemática. Os problemas advindos da seca de 1877, como proliferação de lixo, mendigos, epidemias, insalubridade, delinquência, etc., foram utilizados para se construir um discurso capaz de legitimar a captação de recursos para a modernização da cidade e controle social.

Frederico de Castro Neves ressalta que neste momento se passou a ser questionado o relacionamento com os pobres; e as ideias de trabalho e civilização foram ressignificadas,

12 OLIVENOR, José. "Metrópole da fome": a cidade de Fortaleza na seca de 1877-1879. In: SOUZA, Simone de; NEVES, Frederico de Castro (Orgs.). Seca. Fortaleza: Demócrito Rocha, 2015, p. 50

${ }_{13}$ Idem.

${ }_{14}^{14}$ Ibidem, p. 53.

${ }^{15}$ Ibidem, p. 54. 
assim como o lugar destinado aos pobres e trabalhadores naquela sociedade. ${ }^{16}$ Neves fala ainda de como a seca de 1877 gerou uma mobilização nacional em prol dos retirantes, principalmente na Corte, com subscrições e comissões de socorros em vários pontos do país. Essa mobilização social, norteada pela caridade e "solidariedade cristã" demonstra esses sentimentos na relação entre os pobres e as classes abastadas, assim como sua força organizadora, baseada na "reciprocidade desigual, característica do paternalismo". ${ }^{17}$ Porém, nesse momento de crise do Império e de seus "fundamentos simbólicos e ideológicos", as relações entre Estado e esses trabalhadores pobres serão repensadas. ${ }^{18}$

A atitude dos sertanejos de agirem por conta própria ao saírem do campo (entendido como espaço em que podiam circular e onde possuíam mobilidade restrita de trabalho) para as cidades (onde buscavam a ajuda enviada do governo) assustava as elites da capital que viam esse comportamento como uma ameaça à ordem por elas estabelecida. Além disto, sentiam medo de um descontrole dessas massas. Logo, defendiam a caridade como meio de se assegurar contra o que eles entendiam como uma desordem causada pela chegada dos retirantes.

A preocupação com a ociosidade e a ênfase no trabalho e na caridade como meio de remediá-la continuava até o final do período de secas e quando este chegava ao fim, retornava o estímulo para o regresso desses retirantes para o campo. Nesse sentido, Castro Neves chama a atenção para os diversos sentimentos que nasciam na população em contato com a miséria. Assim como a ideia de barbárie, também havia o sentimento de decadência e degeneração, tanto física quanto moral, que parecia se generalizar naquele momento. Daí advinha o olhar científico, produzindo "verdades" sobre o retirante e sua natureza, considerada sub-humana, que justificava as ações de controle social e a repressão violenta.

Frederico Castro Neves defende, então, que o pacto paternalista entre os "coronéispais-patrões" e seus subordinados, ${ }^{19}$ homens pobres e escravos, de lealdade e apadrinhamento, foi rompido em 1877, quando estes foram deixados à própria sorte, ou emigraram para outras províncias (os escravos foram vendidos) e foi o Estado quem assumiu as obrigações do pacto, como já foi destacado. No entanto, o rompimento do pacto inicial não resulta em um rompimento do tecido social, permanecendo os termos de reciprocidade. Por isso, o direcionamento dos pedidos de assistência ao Estado. A partir daí os próximos "movimentos de multidão" que ocorreriam já encontrariam "estas estruturas de sentimentos razoavelmente estabelecidas e daí por diante deverão, dentro dos termos ditados por elas, negociar com as autoridades urbanas". ${ }^{20} \mathrm{~A}$ seca se transforma assim em uma "chave importante na compreensão da realidade histórica e social do Ceará". ${ }^{21}$

\footnotetext{
16 NEVES, Frederico de Castro. "Desbriamento" e "perversão": olhares ilustrados sobre os retirantes da seca de 1877. Projeto História, São Paulo, n. 27, p. 167-189, dez. 2003.

17 Ibidem, p. 172.

18 Ibidem, p. 173.

${ }^{19}$ Ibidem, p. 100.

${ }^{20}$ Ibidem, p. 101.

${ }^{21}$ Idem.
} 
Essa reflexão nos leva a compreender os mecanismos e discursos da campanha abolicionista que se inicia após a seca de 1877 , onde percebemos uma atitude paternalista dos abolicionistas. Estes concediam as cartas de alforria aos escravos como um presente, aos quais só restavam agradecer. Não estando presente nos discursos dos intelectuais do Instituto do Ceará, que escreveram a história oficial da abolição posteriormente, a resistência e iniciativas dos próprios escravos em busca de sua liberdade. Essa atitude é perceptível em uma fala de Fernando Camara, em 1984, em artigo da Revista do Instituto do Ceará: "Coube à terra de Iracema a primazia de declarar livres os nossos escravos, graças ao movimento encetado pelos intelectuais, através da associação, LIBERTADORA CEARENSE, em favor de tão justa causa".22

Além disso, os elementos constituintes dessa historiografia foram a economia e os aspectos geográficos. Segundo Cícero João da Costa Filho, a historiografia surgiu a partir das condições materiais da província. Estas sempre permeavam as explicações históricas. Assim "não sem razão que os autores mais credenciados, durante o nascimento da historiografia cearense nos anos 60 e 70, instituída e formalizada pelo Instituto do Ceará, são pensadores que atribuem ao meio geográfico a 'determinação' na formação da índole ou caráter do 'tipo' cearense". ${ }^{23}$ Por este motivo, a pobreza material foi a base da cultura e literatura cearense, e segundo Cícero Filho, a fundação do Instituto do Ceará em 1887 endossa essa "identidade", pois seus membros atribuíram grande relevância "às condições materiais da região". ${ }^{24}$ Podemos pensar, neste sentido, que a relação entre o ser humano e o território é marcada também pela atribuição do sentido, de um "significado que é cultural, que é tramado através de símbolos e de alguma forma de linguagem". ${ }^{25}$

Desde meados do século XIX, no discurso formulado pelo Instituto do Ceará, o meio considerado adverso aparece como fator particularizante da personalidade do cearense, tornando-o um forte. Cardoso destaca que essa ideia estaria presente em artigos de órgãos literários e científicos, como A Quinzena, a Revista da Academia Cearense e a Revista do Instituto do Ceará, nas quais se compôs esse modelo de que a seca vencida tornaria o homem sobrevivente, "um ser dotado de um virtuoso senso moral", que conferiu ao cearense um "pendor à disciplina, ao trabalho, resistindo às intempéries, acabando por moldar o seu caráter em prol do progresso, que era o compromisso moral dos novos tempos que não poderia ser esquecido". ${ }^{26}$

Dessa forma, a ideia de que o cearense era forte e resistente por sobreviver a tantas calamidades, contribuiu para a narrativa do próprio movimento abolicionista, que justificava o feito da abolição pelas características intrínsecas ressaltadas pela seca. Além dessas

22 CAMARA, Fernando. A abolição dos escravos e a Igreja do Ceará. In: Revista do Instituto do Ceará. Fortaleza: 1984, p. 117. Grifos nossos.

${ }^{23}$ COSTA FILHO, Cícero João da. Padaria Espiritual: cultura e política em Fortaleza no final do século XIX (1892-1898). 2007. Dissertação (Mestrado) - Universidade de São Paulo, São Paulo, p. 24.

24 Ibidem, p. 25.

${ }^{25}$ ALBUQUERQUE JÚNIOR, Durval Muniz. Preconceito contra a origem geográfica e de lugar: As fronteiras da discórdia. São Paulo: Cortez, 2012, p. 8-9.

${ }^{26}$ CARDOSO, Gleudson Passos. As Repúblicas das letras... Op. cit., p. 75, 78. 
características, o cearense também era amante da liberdade por natureza. Mais ainda, a liberdade era sua vocação. No artigo da Revista do Instituto do Ceará intitulado "Uma data cearense", de Alba Valdez, também vemos esta ideia:

O povo cearense não podia suportar o inominável tráfico que rebaixava parte de seus semelhantes ao nível de alimarias. Envergonhava-o o espetáculo degradante da escravidão [...]. Melindravam-Ihe a consciência as cenas cruéis que desfaziam os doces laços de uma família infeliz, a fuga de desditosos que se internavam nas brenhas, preferindo a convivência dos brutos à de homens insensíveis à sua dor. $\mathrm{E}$ o mesmo dinheiro, produto do braço escravo, queimavaIhe as mãos válidas e honradas, afigurando-se-Ihe criminosa extorsão. Pois ele sabia trabalhar, combater pela vida. Sua enfribatura mais de uma ocasião fora posta à prova: em momento histórico, para defender os brios da Pátria, nos banhados mortíferos do Paraguai; todos os dias, nas florestas virgens da Amazônia, onde os perigos enxameiam no próprio ar. [...] D’aí talvez, sua índole afoita e generosa. Familiarizado desde cedo com a adversidade, ciente de quanto um minuto de amargura intoxica uma existência inteira, desolava-o a excrescência abjeta do cativeiro. Tornava-se mister um movimento que acabasse com aquela vergonha social. A empresa não era fácil e para ela se arregimentavam as mais belas inteligências e as mais decididas energias. Travou-se, por fim, a peleja. ${ }^{27}$

Nos discursos do Instituto, destaca-se como fator que levou à libertação dos escravos apenas a bondade e devotamento intrínsecos do cearense. Devido a esse altruísmo do cearense, a escravidão causava-Ihe vergonha. Dessa forma, por sua benevolência e pela força adquirida na luta com o meio, tinha as características ideais para abolir a escravidão. Sobre esta questão temos a fala de Tácito Teófilo, no artigo da Revista intitulado "Abolição - um ato de fé", no qual ele diz:

Não falta quem afirme que os sobreviventes procuraram desembaraçar-se de um auxiliar que se tornará inútil no momento do desastre, senão fora um encargo mais, um perigo para novas crises por ventura iminentes. O fato, porém explica-se por um sentimento de piedade, que a própria miséria gravou em todos os espíritos. Muitos proprietários viram-se reduzidos a salvar-se, pelo sacrifício de seus escravos ao minotauro da lavoura do sul vendendo-os para o trabalho rude e primitivo, que ali consome inutilmente o tempo e as vidas. $A$ separação custava ordinariamente muitas lágrimas... Foi a mágoa que gerou um ódio profundo à negra instituição. Cada qual se quis por a cobra de novas fraquezas, e a primeira voz pedindo graças para os cativos, achou abertos todos os corações à Justiça e à piedade. ${ }^{28}$

Percebe-se que o autor romanceava o tráfico interprovincial, supondo uma ligação afetiva entre o senhor e o escravo. Dessa forma, o senhor se resentia por causa da separação, ocasionada pela venda de seus escravos para o sul, onde o trabalho era mais "rude", como se no Ceará ele fosse mais brando. A seca, então, tornou o cearense não só forte e resistente como também piedoso.

Sobre a legitimação desse discurso por parte do Instituto do Ceará, Pierre Bourdieu nos esclarece sobre como algumas instituições possuíam os meios de legitimar determinados discursos, inseridas na luta pela identidade regional. Segundo ele nas lutas pela identidade

\footnotetext{
27 VALDEZ, Alba. Uma data cearense... Op. cit., p. 243-244.

${ }^{28}$ TEÓFILO, Tácito. Abolição - um ato de fé. In: Revista do Instituto do Ceará. Fortaleza: Ed. UFC, 1984, p. 18. Grifos nossos.
} 
regional, são desejados os meios de divisão pelos quais se formam e se reconhecem os grupos. Essa divisão legítima consiste no "ato de autoridade" de "circunscrever a região, o território" e de "impor a definição [...] legítima, conhecida e reconhecida, das fronteiras e do território, em suma, o princípio de divisão legítima do mundo social". Pois, nessas lutas, os grupos são estigmatizados e essas divisões territoriais e sociais são arbitrárias, impostas por aqueles que possuem "autoridade". Esta consiste em se afirmar uma verdade, que gera reconhecimento, produzindo "a existência daquilo que se enuncia". ${ }^{29}$

Para Bourdieu ainda devemos considerar o discurso regionalista como performativo, ou seja, tem em vista "impor como legítima uma nova definição de fronteiras e dar a conhecer e fazer reconhecer a região assim delimitada", em oposição a uma definição dominante já existente. ${ }^{30} \mathrm{~A}$ eficácia do discurso performático reside na autoridade de quem o enuncia. Este produz o que está enunciando, mas quem anuncia deve estar imbuído de autoridade para tanto, ou seja, deve estar "autorizado a autorizar". ${ }^{31}$ Consiste também em um enunciado que é fundamentado na objetividade do grupo, ou seja, no reconhecimento e na crença que Ihe confere os membros do grupo, bem como nas características econômicas e culturais que têm em comum. Logo, o poder exercido sobre o grupo, que segundo Bourdieu "se trata de trazer à existência enquanto grupo" é ao mesmo tempo o poder de impor princípios de visão e divisão comuns, ou seja "uma visão única da sua identidade, uma visão idêntica da sua unidade", a partir do discurso oficial. A oficialização tem sua realização completa na manifestação, onde o grupo marginalizado se torna visível para os outros e para si próprio "atestando assim a sua existência como grupo conhecido e reconhecido, que aspira a institucionalização". ${ }^{32}$

Isso posto, compreendemos que a "identidade regional, não é dada pelo espaço onde se nasce, ela emerge de um trabalho de subjetivação". Ou seja, isso passa pelo "plano das interações simbólicas, no plano do sentido e do significado". ${ }^{33}$ A escrita sobre a região é, para Albuquerque Júnior, "um trabalho de elaboração do regional [...] é um trabalho de invenção ou re-invenção do regional ou do local". ${ }^{34}$ Entendemos que era exatamente isso o que buscavam os intelectuais congregados no Instituto do Ceará. A partir da sua posição como instituição reconhecida para emitir discursos científicos, o Instituto se valeu de um aparato discursivosimbólico sobre o legado abolicionista, sobre a seca, sobre a população cearense, que se tornou, em grande medida, marca dominante da região desde então.

\footnotetext{
${ }^{29}$ BOURDIEU, Pierre. A identidade e a representação: elementos para uma reflexão crítica sobre a ideia de região. In: O Poder Simbólico. Rio de Janeiro: Bertrand, 1989, p. 114.

${ }^{30}$ Ibidem, p. 116

${ }^{31}$ Idem.

${ }^{32}$ Idem.

33 ALBUQUERQUE JÚNIOR, Durval Muniz. Receitas Regionais... Op. cit., p. 8.

${ }^{34}$ Ibidem, p. 9
} 


\section{Os legados dos discursos sobre o sertanejo no campo de concentração do Alagadiço}

Voltamos à temática da seca como aparato importante para refletir esse ser regional cearense. Propomos pensar como a seca de 1915, como os discursos formulados desde a criação do Instituto do Ceará, como vimos acima, tornaram-se ações concretas nos sertões a partir de uma ideia criada, por vezes, forjada, sobre essa população.

Desde a seca de 1877, tentou-se organizar espacialmente o sertanejo para que não perambulasse pelas cidades, como mencionado. O medo dessas pessoas, da sua circulação, das doenças, era um dado comum e, inclusive, foi usado pela elite local e pela imprensa como forma de controle dos retirantes que chegavam dos sertões.

Em 1915, a capital Fortaleza tentava manter um ideal de sociedade civilizada, moderna e ordenada. Nesse contexto já se havia criado, em 1909, a Inspetoria de Obras Contra as Secas (IOCS) para atuar nos sertões do Nordeste. A IOCS devia enfrentar os problemas dos sertões, e atuar também em meio às secas. A premissa básica da sua atividade era a criação de obras públicas para melhoramento e distribuição de água, priorizando a construção de açudes e estradas de ferro. Com um organismo criado para tal fim, o contexto da seca de 1915 é outro, diferente ao da criação do Instituto do Ceará e também da seca de 1877. No entanto, de modo geral e mais amplo, as imagens já internalizadas e naturalizadas sobre a população cearense e, principalmente sertaneja, pouco mudou nesse período.

Podemos considerar e refletir como os discursos não se dão apenas pelas vias das narrativas, descontextualizados, desmaterializados da realidade vivida. Pelo contrário, eles fazem parte de um projeto político, de um plano de controle, e com a seca de 1915 temos um exemplo notório dessa questão. O sertanejo era ainda aquele passível de ser controlado, por vezes visto como uma massa amorfa, sem consciência de sua posição social. Assim, ora ele era resignado e forte, ora sofrido e triste, que necessitava da tutela do Estado, ou da caridade de uma elite local. Tal narrativa, não se deu apenas no campo símbolo, ela e se tornou, no ano de 1915, uma política pública concreta. Por isso, nesse ano houve a criação do primeiro campo de concentração do Ceará, em meio à crise climática. ${ }^{35}$ A justificativa para a formação do campo era a necessidade de organizar a distribuição de socorros para os retirantes que invadiam a capital Fortaleza, para que não ficassem espalhados pela cidade. O Alagadiço tornou-se um centro de isolamento dos sertanejos e de controle dos seus corpos.

No entanto, sabemos que a seca é uma questão política e social, e não apenas geográfica. Ela revela tramas que estão por trás da questão climática e que estão relacionadas aos diversos grupos que se beneficiam com uma ideia de um espaço-vítima para pensar os semiáridos, como vimos, inclusive, nas narrativas da Revista do Instituto do Ceará. Era o

\footnotetext{
35 Referimo-nos a esse campo de concentração como o primeiro, porque em 1932 foram criados pelo Governo Federal, por meio do Ministério da Viação e Obras Públicas, sete campos de concentração espalhados estrategicamente pelo Ceará: ao sul, o de Crato, no centro os de Senador Pompeu, Quixeramobim e Cariús, ao norte, o de Ipu e os dois do centro de Fortaleza, Urubu e Tauape.
} 
sertão e a seca que justificavam a pobreza, as doenças, a fome, o desemprego da população sertaneja e era por isso que ela migrava, ou era por isso que ela era forte ou benevolente. Com esse tipo de construção discursiva, se silenciava a desigualdade existente na região que independia da seca, e que era parte constitutiva da relação social do latifundiário com o pequeno produtor (que é o mais atingido no momento de uma crise).

Portanto, a construção discursiva sobre o Ceará, institucionalizada por uma elite letrada cearense, nos mostra como a produção de imagens, de conhecimento, de saberes sobre os cearenses pautadas na imagem do ser sertanejo, do retirante, da seca, do flagelado, do sofrimento, da bondade, da bravura, da resistência, foi uma tentativa real de mistificar essa população e controlá-la em diversos momentos da história da região. Consideramos pensar a criação do campo de concentração dentro dessa perspectiva e como uma forma de separação espacial, como concretização daquilo que Albuquerque Júnior chama de "discurso da estereotipia". ${ }^{36}$ Isso significa que por meio das visões sobre o sertanejo, criadas a partir da seca e aqui, especificamente, concebidas desde as narrativas do Instituto do Ceará, há um "discurso assertivo, imperativo, repetitivo, caricatural" que consagra imagens sobre essa população e justifica, a partir delas, a inferioridade do sertanejo e a necessidade de que fosse dominado, principalmente em períodos de seca. ${ }^{37}$

Dentro dessa conjuntura, o ano de 1915 foi um dos anos de mais desastrosos efeitos climáticos para as populações do Nordeste brasileiro, principalmente para os cearenses, "que, a braços com a miséria extrema, se viram a emigrar em grandes massas para o Norte e Sul do país", ressaltava o presidente do estado do Ceará, à época, Benjamim Barroso, no Almanaque do Ceará. ${ }^{38}$ No entanto, Armando Pinheiro Neto, ao analisar o índice de chuvas desse ano, diz que ele foi "maior que em outros períodos de seca, e os três anos anteriores (1912, 1913 e 1914) foram de altíssima pluviosidade". ${ }^{39}$ O autor, ao comparar o índice de chuva de 1915 com o da grande seca de 1877 e com o período que imediatamente Ihe antecedeu, ressalta que "fica ainda mais clara a desproporção da ocorrência de chuvas em relação a 1915".40 Para Pinheiro Neto, portanto, "pode-se afirmar que a baixa pluviosidade ocorrida em 1915, por si só, não serve para explicar a tragédia que se abateu sobre o Estado". ${ }^{41}$

Dizia Benjamim Barroso que a União, em conjunto com São Paulo, Rio Grande do Sul e o Uruguai, mais a ajuda de particulares em conjunto com a Igreja Católica representada pelo, então, arcebispo do Ceará D. Manoel da Silva Gomes, "acudiram os desesperados apelos do Ceará faminto". ${ }^{42}$ De acordo com a autora Luciara Frota, Dom Manuel viajou ao Rio de Janeiro

\footnotetext{
${ }^{36}$ ALBUQUERQUE JÚNIOR, Durval Muniz. Preconceito contra a... Op. cit., p.13.

37 Idem.

38 INSTITUTO DO CEARÁ, HISTÓRICO, GEOGRÁFICO E ANTROPOLÓGICO (IC). Almanaque Estatístico, Administrativo, Mercantil, Industrial e Literário do Estado Ceará para o ano de 1915. Ceará: Est. Gráfico Urania, 190 ano, 1916 , p. 21.

39 PINHEIRO NETO, Armando. De curral da fome a campo santo: o campo de concentração de retirantes na seca de 1915 em Fortaleza. Dissertação (Mestrado) - Universidade Federal do Estado do Rio de Janeiro, 2014, p.48.

${ }^{40}$ Idem.

${ }^{41}$ Ibidem, p.49.

42 IC. Almanaque Estatístico, Administrativo... Op. cit., p. 21.
} 
e ao Uruguai conseguindo arrecadar os donativos para a seca, estimando-se em 8.000 pesos. ${ }^{43}$ Mas tal "esforço" não foi suficiente e milhares de sertanejos, ao migrarem para Fortaleza, foram confinados em um local que levou o nome de campo de concentração do Alagadiço.

Cabe mencionar que em 1877, quando os sertanejos começaram a se aglomerar em Fortaleza, o governo, para controlá-los, criou abarracamentos espalhados pela capital, para que os sertanejos recebessem assistência. Esses abarracamentos, barracas que ficavam amarradas debaixo de cajueiros, acabaram por se tornar lugar de morte para essas pessoas, visto que eram péssimas as condições de higiene e de distribuição de alimentos. A ideia era usar essa mão de obra de maneira que não se tornassem mendigos a pedir esmolas, como mencionado no tópico anterior. No entanto, não havia trabalho nas obras para quantidade de sertanejos que saiam dos sertões. Fora esse fato, muitos dos alimentos apodreciam e muitas doenças se disseminaram pelos locais.

Ofícios vindos diretamente de Fortaleza atestavam a criação dos abarracamentos para organizar e conter a multidão de emigrantes indigentes e mostravam as condições de insalubridade dos distritos onde havia as barracas. No ofício de $1^{\circ}$ de outubro de 1877 , o comissário do $2^{\circ}$ distrito que ficava no Pajeú e no Alto da Pimenta relatava ao presidente da província que foram construídas "110 palhoças, sendo no Pajeú, 45" além de uma casa maior pertencente à província, e no "Alto da Pimenta 65 e mais uma igualmente coberta de telha com 300 palmos de frente e que foi ultimamente construída para enfermaria dos emigrantes. O total de emigrantes de ambas as secas é de $1.688^{\prime \prime} .44$

Levando em consideração que os abarracamentos eram espalhados em distritos, a Comissão do 50 distrito em ofício pedia também fornecimento de madeiras para os abarracamentos. No ofício de 14 de setembro de 1877, relatava-se o estado dos alimentos, que em grande parte estavam sem condições de consumo. Assim, dizia-se: "A farinha, além da má qualidade, não se poderão tragar pelo mau gosto e pugnante cheiro, isso 88 porque havia se molhado por água salgada na ocasião do embarque". ${ }^{45}$

Neste sentido, em 1877, a desorganização da distribuição da população dos sertões em diversos distritos acabou dificultando os socorros e a higienização de cada localidade. As condições de higiene dos abarracamentos eram péssimas, porque os sertanejos ficavam confinados em um pequeno terreno com várias barracas localizadas a esmo, e muitos ofícios pediam copiosamente enfermarias, distribuição de alimentos e trabalho para a população.

Apesar de toda essa narrativa vinda desses ofícios, a preocupação principal não era, necessariamente com a vida dessas pessoas, mas com a moralidade e controle dekas, em uma Fortaleza que se pretendia moderna e civilizada. Também se trata de um contexto em que teorias cientificistas, evolucionistas e social-darwinistas viam "na natureza ou no meio e a raça

\footnotetext{
${ }^{43}$ FROTA, Luciara Silveira de Aragão. Documentação Oral e a temática da Seca. Brasília: Centro Gráfico, 1985, p. 174.

${ }^{44}$ ARQUIVO PÚBLICO DO ESTADO DO CEARÁ (APEC). Ofício do Comissário do $2^{\circ}$ Distrito ao presidente da província Caetano Estellita. Fortaleza, 1.0 de outubro de 1877.

${ }^{45}$ APEC. Ofício, Informe de compras ao presidente da província do Ceará. Palácio do Governo. Fortaleza, 14 de dezembro de 1877.
} 
[...] como conceitos fundamentais para pensar o comportamento humano e as relações sociais". ${ }^{46}$ Tais concepções "vão ser responsáveis pela elaboração de imagens e falas em torno do homem do Norte, notadamente desse vitimado pela seca", como o retirante, o degredado, o flagelado. ${ }^{47}$ Muitos desses discursos ainda eram comuns nos anos posteriores, como 1915 e 1920, e "em muitos deles o atraso da região, sua crise econômica social, eram atribuídas à composição de sua população, majoritariamente mestiça [...]. Ao mestiço, notadamente, mulato, era associada a ideia de que era preguiçoso, resistente ao trabalho regular" ${ }^{48}$ Nesse sentido, podemos refletir que o campo de concentração do Alagadiço também está relacionado diretamente a essas ideias racialistas e cientificistas sobre o ser nordestino.

O terror das secas e da massa de retirantes nas capitais se tornava ainda pungente nas notícias dos jornais do Sul. No Correio da Manhã, periódico do Rio de Janeiro, uma reportagem de 1915 relatava que o êxodo da população do Ceará era cada vez mais intenso e seu aumento chegava a ser assustador. Descrevia em números a quantidade de pessoas a vagar e pedir ajuda do governo em Fortaleza. No campo do Alagadiço, segundo o jornal, havia 5.411 retirantes e nas ruas perambulavam mais. Descreviam que os trens que vinham do interior traziam um grande número de sertanejos "em seus bandos" e que era cerca de 80 mil o número de pessoas que necessitavam de auxílio para não morrem de fome. Tal número, segundo o jornal, elevar-se-ia para 120 mil pessoas, antes do fim do ano. O jornal reivindicava que era necessário empregar cerca de "15 mil operários e em dezembro elevar este número para 23 mil aproximadamente". ${ }^{49}$ Desta forma, os periódicos acabavam por aterrorizar ainda mais a população, com as notícias sobre a fome e as migrações. Na reportagem citada, o sertanejo já era chamado de operário e a notícia clamava que eles fossem empregados em obras públicas. Por conseguinte, o medo era a melhor arma para manter o flagelado longe das elites das cidades, e o trabalho a melhor forma de dignificá-los do mal da miséria.

Logo, o campo de concentração podia ser um regulador da entrada da população dos sertões, que para o governo era acostumada a uma vida "sem disciplinas" de trabalho, nas construções de açudes e estradas de ferro. Esse era o argumento principal, era necessário que o sertanejo se acostumasse a trabalhar nas obras. O sertanejo passava a ser designado como operário das obras, e consideramos que a partir disso houve uma tentativa de modificação das relações de trabalho, da sua relação com a natureza, do seu cotidiano de vida, pela ação científica e modernizadora da Inspetoria. Falamos científica, porque havia um corpo técnico de engenheiros que justificava ações diversas da IOCS de forma técnica, baseadas na ciência da engenharia da época.

Dessa forma, a existência do campo do Alagadiço foi justificada precisamente por um relatório do presidente do estado Benjamim Barroso, no qual o mesmo colocava que havia excedido o número de três mil pessoas no Passeio Público, localizado em Fortaleza, assim que

\footnotetext{
${ }^{46}$ ALBUQUERQUE JÚNIOR, Durval Muniz. Preconceito contra a... Op. cit., p. 94.

47 Idem.

${ }^{48}$ Ibidem, p. 116.

49 O êxodo da população cearense. Correio da Manhã, Rio de Janeiro, Ano XV, n. 6.098, 5 nov. 1915, p. 6.
} 
a seca assolou em 1915 e, por isso, era necessário retirar as populações migrantes e colocálas no Alagadiço. Segundo Rodolfo Teófilo, farmacêutico que viveu no período das secas de 1877 e 1915, "ficou resolvido que os retirantes seriam recolhidos a uma grande área arborizada e cercada nos subúrbios da Capital". ${ }^{50}$ A propriedade do Alagadiço, narrou Barroso, era do Sr. João de Pontes Medeiros, que o cedeu para que o governo "para fim tão humanitário, criasse o Campo de Concentração" que "por muito tempo comportou permanentemente mais de oito mil pessoas". ${ }^{51}$ De acordo com Armando Pinheiro Neto, "o Campo de Concentração surge na verdade com o argumento moralista de coibir a prostituição ou 'atos libidinosos' e também para prevenir a mendicância, saques e outras ações de massa empreendidas pela multidão de famintos". Para o autor, o que norteava a feitura desse campo era, em realidade, "a proteção da propriedade privada, da ordem pública e da moral e os bons costumes". ${ }^{52}$

Para tal propósito, a organização do Alagadiço deu-se da seguinte forma: foram feitas instalações elétricas que facilitariam a fiscalização do local, e os homens e rapazes sadios, apesar de abatidos pela fome, eram mandados para trabalhos de terraplanagem nas ruas e praças da cidade. Para compensar tal trabalho que, segundo Barroso, era de poucas horas por dia, tinham em contrapartida alimento, auxílio médico e farmacêutico. Havia também distribuição de roupas não só pelo governo, mas por particulares. Para completar, teriam no campo de concentração acompanhamento espiritual do Arcebispo de Fortaleza, Frei Ignácio, o que revela como a Igreja Católica foi uma forte aliada na construção da ideia de moralidade na vida dos sertanejos, que vivam sob a égide de seus próprios conceitos sobre religião, moral e costumes.

Benjamim Barroso deixou claro que os trabalhadores eram separados entre os mais fortes e os mais fracos, e os mais fortes, segundo ele, eram também os que possuíam pequenos lotes de terra no interior e seriam encaminhados para obras maiores, como nas estradas de ferro, onde receberiam um salário. Os menos saudáveis, mas ainda aptos aos trabalhos, eram colocados em obras menores, sendo assim, só o trabalho lhes garantia o direito à alimentação e assistência médica. Já os que não tinham nenhuma condição de trabalhar não foram mencionados na documentação, o que podemos inferir, a partir dessa organização, é que até aqueles considerados "aptos ao trabalho" podiam não ter as mínimas condições para exercê-lo. Esse tipo de imposição ao sertanejo se constituiu como trabalho forçado e contribuiu para as muitas mortes nas obras e no próprio campo de concentração. Além disso, aqueles vistos como "não aptos" acabavam vivendo à própria sorte, e morriam pelas péssimas condições de higiene.

O que as elites e Barroso desejavam, como já afirmamos, é que os sertanejos fossem isolados, vigiados, para que o local não se tornasse um centro de promiscuidade. 0 discurso da

\footnotetext{
50 TEÓFILO, Rodolfo. A Seca de 1915. Fortaleza: Ed. UFC, 1980, p. 52.

51 BIBLIOTECA NACIONAL - RIO DE JANEIRO (BN-RJ). Hemeroteca Digital. BARROSO, Benjamim. Relatórios dos presidentes dos estados brasileiros. Fortaleza, 1915, p. 7, 8.

52 PINHEIRO NETO, Armando. De curral da fome... Op. cit., p. 77.
} 
moralização foi via possível de controle e de segregação dos espaços. Outra questão importante, é que os retirantes eram submetidos ao humilhante fato de que para que recebessem alimentos e ajuda médica era necessário que trabalhassem. Ora, o que Ihes garantia tal "benefício", portanto, era o mérito do trabalho, a ocupação dos seus braços vistos como ociosos. A condicionante trabalho-salário, trabalho-assistência do governo, mostra como, de fato, o que se queria era manter o sertanejo em trabalho físico árduo, ocupando seus braços, mentes e corpos..$^{53}$

Rodolfo Teófilo advertia à Benjamim Barroso que "aglomerar os retirantes era matálos". ${ }^{54} \mathrm{Em}$ seus escritos, explicava que não compreendia porque o Alagadiço convencionou-se chamar de campo de concentração, já que os retirantes foram postos a esmo em uma pequena área, expostos também em abarracamentos. Teófilo sempre que tratava do tema colocava o campo de concentração entre aspas. O próprio farmacêutico relatou que em sua primeira visita ao Alagadiço conseguia perceber que seria um lugar de mortes e se tornaria prontamente um "Campo Santo". Dizia ele: "em um quadrilátero de quinhentos metros de face estavam encurralados cerca de sete mil retirantes" que foram se abrigando embaixo dos cajueiros ou alguns conseguiam armar uma barraca que, segundo ele, era tão paupérrima que não tampava os raios de sol. ${ }^{55}$ Criticava ainda a cozinha construída a esmo e o local onde eram depositadas as fezes, que ficavam expostas perto dos abarracamentos e às moscas.

Em seu romance $O$ Quinze, Rachel de Queiroz também narrou a saga dos sertanejos na seca de 1915 e tratou do tema do campo de concentração. Há um trecho em que a personagem Conceição retratava os aspectos do lugar em duas idas para ajudar na entrega dos socorros:

\begin{abstract}
o mau cheiro do campo parecia mais intenso [...]. Quando transpôs o portão do Campo, e se encostou a um poste, respirou mais aliviada. Mas, mesmo de fora, que mau cheiro se sentia! Através da cerca de arame, apareciam-Ihe os ranchos disseminados ao acaso. Até a miséria tem fantasia e criara ali os gêneros de habitação mais bizarros. Uns debaixo dum cajueiro, estirados no chão, quase nus, conversavam. Outros absolutamente ao tempo, apenas com a vaga proteção de uma parede de latas velhas, rodeavam um tocador de viola. ${ }^{56}$
\end{abstract}

Não cabe, neste artigo, uma análise da obra de Rachel de Queiroz. No entanto, ela pode nos mostrar a percepção que a autora desejou mostrar sobre o campo de concentração, que muito se assemelha com os documentos aqui analisados. Neste trecho muitos sertanejos

\footnotetext{
53 Cabe ressaltar que os sertanejos não foram uma massa amorfa que não se rebelaram contra as péssimas condições em que viviam. Faz-se fundamental evidenciar o lugar de reivindicação sertaneja que, principalmente, o autor Frederico de Castro Neves propõe analisar em diversos dos seus trabalhos. De acordo com o autor, em 1923, por exemplo, muitos sertanejos tentaram assaltar trens em Senador Pompeu. Neves nota que os sertanejos aprenderam a manifestar-se e suas reivindicações passaram a ter a praça pública como protesto. Com isso, negociavam por meio de pressões diretas, saques e exposição das suas misérias. MELO, Leda Agnes Simões de. O trabalho em tempos... Op. cit., p. 104. Sobre os saques e outras formas de manifestações dos sertanejos, ver: NEVES, Frederico de Castro. A multidão e a História: Saques e outras ações de massa no Ceará. 1998. Tese (Doutorado) - Universidade Federal Fluminense, Niterói (RJ).

${ }^{54}$ TEÓFILO, Rodolfo. A Seca de 1915... Op. cit., p. 52.

${ }^{55}$ Ibidem, p. 60.

${ }^{56}$ QUEIROZ, Raquel. O Quinze. Rio de Janeiro: José Olympio, 2013, p. 63.
} 
viviam sem condições mínimas de higiene: "o mau cheiro do campo parecia intenso", escreveu Queiroz.

Consideramos, portanto, que a ideia de concentrar esses indesejados da seca revela que no Brasil a pobreza tratada como criminalidade, é um fato que perpassa a história. 0 campo de concentração do Alagadiço pode ser visto dentro dessa assertiva: o sertanejo, o pobre, devia ser aprisionado, isolado, porque "seus corpos poderiam tornar-se focos de contaminação, e suas práticas higiênicas vistas como atrasadas e moralmente inaceitáveis (prostituição) eram incompatíveis com o cotidiano de ordem e higiene de Fortaleza". ${ }^{57}$

A própria vigilância do local que era cercado por arame farpado, e as próprias condições de insalubridade em que eram expostos os sertanejos, exemplificam como o problema da seca em si passava a ser secundário mediante certo pavor da circulação de retirantes por Fortaleza. Cabia, como medida principal, acalmar os ânimos dos flagelados, controlando suas ações para que não incomodassem as elites locais e nem o próprio andamento/normalidade de Fortaleza, e sua necessidade de se fazer ver avançada, limpa, ordenada.

Percebemos que algumas dessas prerrogativas já existiam no seio da elite letrada do Instituto do Ceará, principalmente no que se refere à necessidade de construir uma imagem sobre o sertanejo que escamoteava certo desejo de que as estruturas vigentes não fossem modificadas e se mantivesse, a partir disto, um status quo. Ademais, Kleiton de Sousa Moraes esclarece que os engenheiros responsáveis pela Inspetoria de Obras se voltaram para os sertões com "o dilema de transformar o espaço onde a natureza mantinha-se irredutível, reinando soberana. Travar-se-ia ali mais uma batalha homem versus natureza". ${ }^{58}$ Batalha esta que estaria vencida nas cidades, locais onde estariam as ferramentas possíveis para o progresso nacional.

Nesses aspectos, acreditamos que a imagem do sertanejo visto ora como o indesejado, o outro, e ora como forte e piedoso, ou mesmo de um sertão onde uma natureza era culpabilizadora da desigualdade existente, foi uma construção discursiva estruturada historicamente. Tais narrativas se tornavam caras a essa população, o que contribuiu para que se efetivasse e se legitimasse como viável uma medida segregadora e excludente como o campo de concentração da seca de 1915.

\section{Considerações finais}

Vimos neste artigo que a criação do Instituto do Ceará, e a partir dele a tentativa da escrita da história da região, foi um passo importante para o entendimento do que a elite cearense gostaria de escrever sobre si, sobre os seus, suas conquistas e, principalmente sua singularidade frente a outras províncias do país. No entanto, o fizeram por meio da criação de

\footnotetext{
${ }^{57}$ PINHEIRO NETO, Armando. De curral da fome... Op. cit., p. 80.

${ }^{58}$ MORAES, Kleiton de Sousa. O sertão descoberto aos olhos do progresso: a Inspetoria de Obras Contra as Secas (1909-1918). 2010. Dissertação (Mestrado em História Social) - Universidade Federal do Rio de Janeiro, Rio de Janeiro, p. 49.
} 
estereótipos que legitimaram imagens sobre a região, capazes de se afirmarem ainda na atualidade.

Para este trabalho, enfatizamos a relação intrínseca entre o pioneirismo da abolição da escravatura no Ceará e a seca. A partir da ideia de que a seca havia transformado o cearense em forte e abnegado, por resistir às privações trazidas pela mesma, era ele também quem podia, de fato, abolir a escravidão anos mais tarde. A natureza, o tinha transformado em um ser benevolente para com os demais, e resistente a qualquer sofrimento. Ao mesmo tempo, o sertanejo era visto como aquela população que não se encaixava na dinâmica do progresso e da modernidade dos centros urbanos e que por isso devia ser vigiado e controlado.

Essa construção "imagético-discursiva", como ressalta Albuquerque Júnior, adentrou o século XX e foi usada para legitimar, inclusive, o isolamento de retirantes em campos de concentração, como no caso analisado do campo do Alagadiço na seca de $1915 .{ }^{59}$ Nesse contexto, além da natureza ainda ser a causadora dos infortúnios dos sertões, o sertanejo incomodava quando migrava para Fortaleza, e desordenava o belo que a cidade desejava compor naquele contexto. Concentrar o retirante era a melhor saída de controle dos seus corpos e costumes. Por mais que ele fosse visto como forte e resistente, inclusive por isso ele podia viver privações como os campos de concentração, ele ainda era visto como o diferente do litoral, da civilização, era o outro que necessitava da ajuda humanitária do governo e de uma elite local, que se faziam crer salvadores dessas populações. Vale destacar que esse tipo de narrativa, inclusive, deu origem à própria construção da região Nordeste, produzindo no imaginário popular uma visão da região ligada à escassez, à necessidade e a uma "eterna" ausência de prosperidade.

Pensamos, a partir desta análise, que urge superar imagens e discursos estereotipados sobre a região Nordeste, e neste caso específico, sobre a população cearense. Faz-se necessário questionar, desnaturalizar, sempre que possível, aquilo que é dado, entendendo que as narrativas produzem memória e repercutem imaginários. Para isto, precisamos entender como certas construções discursivas sobre uma região são forjadas, e quais intenções e relações de poder estão associadas intrinsecamente a tais criações. Uma região, neste sentido, é constituída por disputas de poder, que são também simbólicas e subjetivas.

\footnotetext{
${ }^{59}$ ALBUQUERQUE JÚNIOR, Durval Muniz. A invenção do Nordeste e outras artes. São Paulo: Cortez, 2011, p. 342.
} 


\section{Referências}

\section{Fontes}

\section{Documentos Impressos}

BIBLIOTECA NACIONAL - RIO DE JANEIRO. Hemeroteca Digital. BARROSO, Benjamim. Relatórios dos presidentes dos estados brasileiros. Ceará, 1915.

INSTITUTO DO CEARÁ, HISTÓRICO, GEOGRÁFICO E ANTROPOLÓGICO. Almanaque Estatístico, Administrativo, Mercantil, Industrial e Literário do Estado Ceará para o ano de 1915. Ceará: Est. Gráfico Urania, $19^{\circ}$ ano, 1916.

SOUZA, José Ayres de. Relatório dos trabalhos executados durante o ano de 1915. Apresentado a 15 de julho de 1916 ao Sr. Ministro da Viação e Obras Publicas, Dr. Augusto Tavares de Lyra, pelo Inspetor Interino José Ayres de Souza. Rio de Janeiro: Imprensa Nacional 1917.

\section{Documentos Manuscritos}

\section{ARQUIVO PÚBLICO DO ESTADO DO CEARÁ}

Ofício do Comissário do $2^{\circ}$ Distrito ao presidente da província Caetano Estellita. Fortaleza, 1.0 de outubro de 1877.

Ofício, Informe de compras ao presidente da província do Ceará. Palácio do Governo. Fortaleza, 14 de dezembro de 1877.

\section{Periódicos}

CAMARA, Fernando. A abolição dos escravos e a Igreja do Ceará. Revista do Instituto do Ceará, Fortaleza, 1984.

O êxodo da população cearense. Correio da Manhã, Rio de Janeiro, ano XV, n. 6.098, 5 nov. 1915.

TEÓFILO, Tácito. Abolição - um ato de fé. Revista do Instituto do Ceará. Fortaleza: Ed. UFCE, 1984.

VALDEZ, Alba. Uma data cearense. Revista do Instituto do Ceará. Fortaleza: Ed. UFCE,1984.

\section{Bibliografia}

ALBUQUERQUE JÚNIOR, Durval Muniz. A invenção do Nordeste e outras artes. São Paulo: Cortez, 2011.

ALBUQUERQUE JÚNIOR, Durval Muniz. Preconceito contra a origem geográfica e de lugar: As fronteiras da discórdia. São Paulo: Cortez, 2012. 
ALBUQUERQUE JÚNIOR, Duval Muniz. Receitas Regionais: a noção de região como um ingrediente da historiografia brasileira ou o regionalismo como um modo de preparo historiográfico. Anais do [...] XIII Encontro de História da ANPUH-Rio. Seropédica, RJ: ANPUH-Rio, 2008.

BOURDIEU, Pierre. A identidade e a representação: elementos para uma reflexão crítica sobre a ideia de região. In: O Poder Simbólico. Rio de Janeiro: Bertrand, 1989.

CARDOSO, Gleudson Passos. As Repúblicas das letras cearenses: literatura, imprensa e política (1873-1904). 2000. Dissertação (Mestrado) - Pontifícia Universidade Católica de São Paulo, São Paulo.

COSTA FILHO, Cícero João da. Padaria Espiritual: cultura e política em Fortaleza no final do século XIX (1892-1898). 2007. Dissertação (Mestrado) - Faculdade de Filosofia, Letras e Ciências Humanas da Universidade de São Paulo, São Paulo.

FREIRE, Camila de Sousa. O Instituto do Ceará e a identidade regional a partir do movimento abolicionista cearense (1884-1956). 2018. Dissertação (Mestrado em História Social) Universidade do Estado do Rio de Janeiro, São Gonçalo (RJ).

FROTA, Luciara Silveira de Aragão. Documentação Oral e a temática da Seca. Brasília: Centro Gráfico, 1985.

MARTINS, José de Souza. Os camponeses e a política no Brasil. As lutas sociais no campo e seu lugar no processo político. Petrópolis, RJ: Vozes, 1983.

MELO, Leda Agnes Simões de. O trabalho em tempos de calamidade: a Inspetoria de Obras nos campos de concentração do Ceará (1915 e 1932). 2015. Dissertação (Mestrado em Ciências Sociais em Desenvolvimento, Agricultura e Sociedade) - Universidade Federal Rural do Rio de Janeiro, Seropédica (RJ)

MORAES, Kleiton de Sousa. O sertão descoberto aos olhos do progresso: a Inspetoria de Obras Contra as Secas (1909-1918). 2010. Dissertação (Mestrado em História Social) Universidade Federal do Rio de Janeiro, Rio de Janeiro.

NEVES, Frederico de Castro. "Desbriamento" e "perversão": olhares ilustrados sobre os retirantes da seca de 1877. Projeto História, São Paulo, n. 27, p. 167-189, dez. 2003.

OLIVENOR, José. "Metrópole da fome": a cidade de Fortaleza na seca de 1877-1879. In: SOUZA, Simone de; NEVES, Frederico de Castro (Orgs.). Seca. Fortaleza: Demócrito Rocha, 2015.

PINHEIRO NETO, Armando. De curral da fome a campo santo: o campo de concentração de retirantes na seca de 1915 em Fortaleza. 2014. Dissertação (Mestrado) - Universidade Federal do Estado do Rio de Janeiro, Rio de Janeiro.

QUEIROZ, Rachel. O Quinze. Rio de Janeiro: José Olympio, 2013.

ROLNIK. Raquel. A cidade e a lei. Legislação, política urbana e território na cidade de São Paulo. São Paulo: FAPESP, 1997.

SILVA, Ana Paula Barcelos Ribeiro da. "Nem História nem mesmo Chronica": escrita da história, identidade e integração nacional no intercâmbio entre o IHGB e o Instituto do Ceará (1889-1931). Revista do Instituto Histórico e Geográfico Brasileiro, Rio de Janeiro, ano 177, n. 471, p. 101-124, abr.-jun. 2016.

TAVARES, M. C.; ANDRADE, M. C.; PEREIRA, R. (Entrevistadores). Seca e Poder: entrevista com Celso Furtado. São Paulo: Fundação Perseu Abramo, 1998.

TEÓFILO, Rodolfo. A Seca de 1915. Fortaleza: Ed. UFC, 1980. 
TODOROV, Tzvetan. A vida em comum: Ensaio de Antropologia Geral. São Paulo: Ed. Unesp, 2014. 